\title{
Aplikasi Monitoring Energi Shs Off-Grid Menggunakan Lora
}

\author{
Satrio Yudho'; Tony Koerniawan ${ }^{2}$ \\ ${ }^{1,2}$ Institut Teknologi PLN \\ ${ }^{1}$ satrio@itpln.ac.id
}

\begin{abstract}
The manner of efficiency and effective of power usage is the main objective in electricity consumption, one major steps to control the usage is by providing a monitoring to aim the power usage data and process it to information needed. Internet of Things benefit in power and electricity has involved sensors to work as data reader continuously. LoRa or well known as Long Range radio communication system work with chirp spread spectrum which work from 920 to $923 \mathrm{Mhz}$ in Indonesia. This paper presents implementation of LoRa system to support the prototype of energy monitoring in Solar Home System off-grid
\end{abstract}

Keywords: Energy Monitoring, SHS off-grid, LoRa

\begin{abstract}
Abstrak
Penggunaan energi listrik yang terkendali merupakan tujuan dari efisiensi dan efektifitas. Langkah awal untuk dapat mengendalikan penggunaan tersebut adalah dengan melakukan monitoring secara periodic guna mendapatkan data yang dapat diolah menjadi informasi. Salah satu tujuan pengembangan Internet of Things dalam bidang ketenagalistrikan adalah dengan melibatkan sensor untuk membaca data kelistrikan secara kontiyu. LoRa merupakan teknologi komunikasi data berbasis chirp spread spectrum dengan kemampuan bekerja pada frekwensi 920 hingga $923 \mathrm{Mhz}$ di Indonesia. Tujuan penelitian ini adalah untuk membuat sebuah purwarupa sistem monitoring energi listrik pada solar home system menggunakan teknologi sensor serta komunikasi nirkabel Long Radio (LoRa) untuk dapat bekerja secara ringan dan akurat.
\end{abstract}

Kata kunci: Sistem monitoring Energi, SHS off-grid, LoRa 


\section{PENDAHULUAN}

Perkembangan Internet of Things yang ditandai dengan bermunculannya berbagai jenis teknologi sensor dan actuator semakin memberikan peluang untuk peningkatan kualitas hidup manusia. Penerapan teknologi tersebut telah dapat dilihat di beberapa bidang yang salah satunya adalah dalam kelistrikan. Listrik merupakan energi yang tidak bisa lepas dari kehidupan manusia, keberadaan listrik menjadi faktor penentu berjalannya teknologi berbasis komputasi dan elektronik.

Keterlibatan teknologi sensor untuk membaca arus dan tegangan dalam rangka melakukan pengawasan atau monitoring energi listrik telah dilakukan oleh[1] menggunakan model komunikasi berbasis Wi-Fi dan menggunakan tampilan informasi berupa LED Display. Teknologi Wi-Fi memiliki kelebihan yakni bandwith yang besar, namun disertai kekurangan seperti konsumsi energi yang besar dan jangkauan terbatas pada penerimaan dengan satu access point.

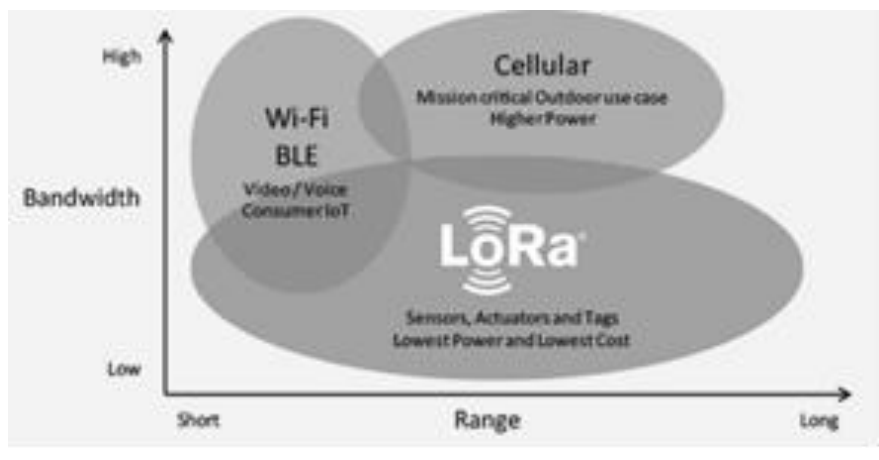

Gambar 1. Perbandingan LoRa dan Wifi

LoRa atau dikenal dengan Long Range adalah system komunikasi yang dikembangkan oleh semtech sebagai inovasi dalam pengembangan Internet of Things[2] , publikasi terkait LoRa dalam Bidang kelistrikan khususnya smart meter[3] telah dilakukan oleh Wibisono dalam penelitian tersebut menyebutkan bahwa penggunaan LoRa pada Smart Meter sangat reliable mencapai persentase tertinggi untuk stabilitas komunikasi data dengan mode dua arah.

Tabel 1. Jangkauan LoRa

\begin{tabular}{|c|c|c|}
\hline Spread Factor & Jangkauan & Bitrate (detik) \\
\hline 7 & 1 hingga 100 Meter & 5469 \\
\hline 8 & 1 hingga 500 Meter & 3125 \\
\hline 9 & 1 hingga 500 Meter & 1758 \\
\hline 10 & 1 hingga 500 Meter & 977 \\
\hline 11 & Lebih dari 500 Meter & 537 \\
\hline 12 & Lebih dari 500 Meter & 293 \\
\hline
\end{tabular}

Tabel diatas menunjukkan karakteristik jangkauan dari setiap End Node (Sensor) LoRa terhadap Gateway (penerima), dengan sebuah Gateway, jangkaun yang terjauh yang dapat dicapai adalah lebih dari 500 Meter. Data tersebut tentu saja mempengaruhi kemampuan dalam pengiriman data yang ditunjukkan dengan Bit Rate dari setiap End Node. Semakin jauh jangkauan yang diinginkan akan berdampak pada semakin kecil jumlah data yang dapat ditransmisikan.

Selain Spread Factor, secara umum transmisi berbasis nirkabel memiliki beberapa parameter seperti Receive Signal Strength Indicator (RSSI)[4] dan Signal Noise Ratio (SNR) yang mempengaruhi kualitas penerimaan data dari setiap end Node menuju Gateway. 


\section{Energi dan Kelistrikan: Jurnal Ilmiah}

Vol. 13, No. 1, Januari - Juni 2021, P-ISSN 1979-0783, E-ISSN 2655-5042

https://doi.org/10.33322/energi.v13i1.1149

Sistem monitoring Energi Listrik dilakukan dengan cara mengukur tiga hal yakni, Arus, Voltase dan Power. Data tersebut dibaca oleh end Node LoRa dan kemudian dikirmkan melalui Gateway untuk selanjutnya dibaca oleh aplikasi berbasis web sebagai informasi berbasis grafis untuk melihat perkembangan penggunaan listrik.

\section{METODE/PERANCANGAN PENELITIAN}

Metode ini merupakan pengembangan dari publikasi sebelumnya yakni desain konseptual sistem monitoring energi berbasis Long Radio Communication (LoRa) [5],dalam penelitian ini terbagi atas tiga Langkah utama, sebagai berikut ini:

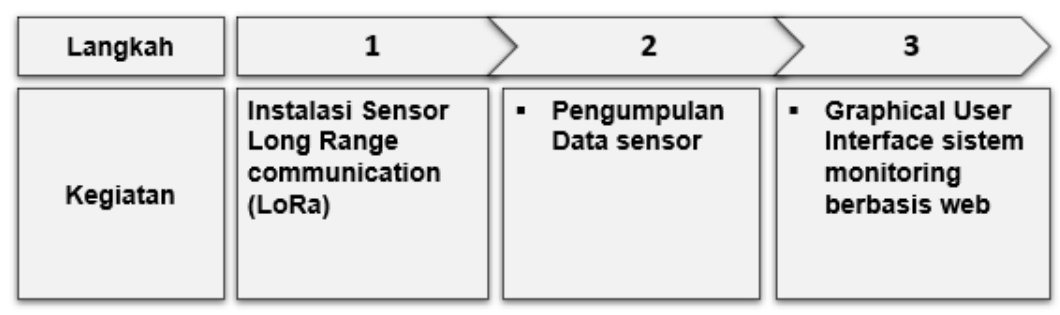

Gambar 2. Metode Penelitian

\subsection{Instalasi sensor LoRa}

Sistem LoRa berkerja dengan minimal satu buah end Node dan satu Gateway, skema yang kami buat dalam penelitian ini adalah menggunakan satu buah LoRa Shield berbasis microcontroller SX76S dengan kombinasi sensor Arus dan Tegangan PZEM004T dan terhubung pada sebuah Gateway. Sebagai berikut:

\section{A. LoRa S76S shield dan Gateway}

Shield LoRa SX76S dikonfigurasikan untuk berkerja pada Spread Factor dan Channel yang disesuaikan dengan Gateway (Gemtek). Penetapan konfigurasi tersebut dibuat menggunakan perintah built in pada sistem LoRa dengan menggunakan command berikut ini:

Tabel 2. Jangkauan LoRa

\begin{tabular}{|l|c|l|}
\hline \multicolumn{1}{|c|}{ Fungsi } & Jangkauan & \multicolumn{1}{c|}{ Nilai } \\
\hline $\begin{array}{l}\text { Pengaturan } \\
\text { Spreading Factor }\end{array}$ & > rf set_sf $n n$ & nn berisi nilai spreading factor \\
\hline Pengaturan & >>rfset_freq & Berisi Frekwensi gelombang \\
Frequency & 915000000 & $\begin{array}{l}\text { radio yang diperkenankan yakni } \\
\text { 915 Mhz }\end{array}$ \\
\hline $\begin{array}{l}\text { Pengaturan Channel } \\
\text { Gateway }\end{array}$ & > mac set_ch_freq 2 & $\begin{array}{l}\text { Pengaturan untuk channel di } \\
\text { Gateway pada frekwensi radio } \\
\end{array}$ \\
& 915000000 & yang dituju. \\
\hline
\end{tabular}

\section{B. Sensor PZEM004T}

Pembacaan energi listrik dilakukan dengan menggunakan Sensor Arus dan Tegangan PZEM004, kapasitas pengukuran sensor tersebut adalah sebagai berikut: 
Tabel 3. Spesifikasi Sensor PZEM004

\begin{tabular}{|c|c|c|}
\hline Parameter & Jangkauan & Akurasi \\
\hline Voltase & $80 \sim 260 \mathrm{~V}$ & $0.5 \%$ \\
\hline Current & $0 \sim 100 \mathrm{~A}$ & $0,5 \%$ \\
\hline Active Power & $0 \sim 23 \mathrm{~kW}$ & $0,5 \%$ \\
\hline
\end{tabular}

Sistem komunikasi data Sensor menggunakan model Universal Asynchronous Receiver Transmitter (UART) dengan RS485 yang dikenal dengan Serial Communication, protocol komunikasi ini menggunakan nilai Baudrate 9600.

\subsection{Pengumpulan Data Sensor}

Pengumpulan data sensor dilakukan dengan menggunakan protocol komunikasi data Message Queueing Telemetry atau dikenal dengan MQTT[6] dan meneruskan data tersebut ke dalam bentuk yang dapat dimengerti oleh Protokol Internet (IP).

\subsection{Graphical User Interface Sistem Monitoring}

Data yang diteruskan oleh protocol komunikasi melalui Internet Protocol akan diteruskan menjadi informasi yang dapat diakses melalui computer menggunakan browser, penyajian informasi dilakukan dalam bentuk grafis dengan tujuan agar informasi yang ditampilkan menjadi lebih mudah untuk dilihat. Pembuatan GUI (Graphical User Interface) ini menggunakan Hypertext Markup Language atau dikenal dengan HTML.

\section{HASIL DAN PEMBAHASAN}

Skema sistem monitoring SHS off-grid terdiri atas tiga rangkaian utama yakni, Sistem LoRa yang terdiri atas dua komponen penting yakni sensor dan Shield komunikasi, kedua adalah protocol komunikasi dan ketiga adalah media penayang informasi berbasis web.

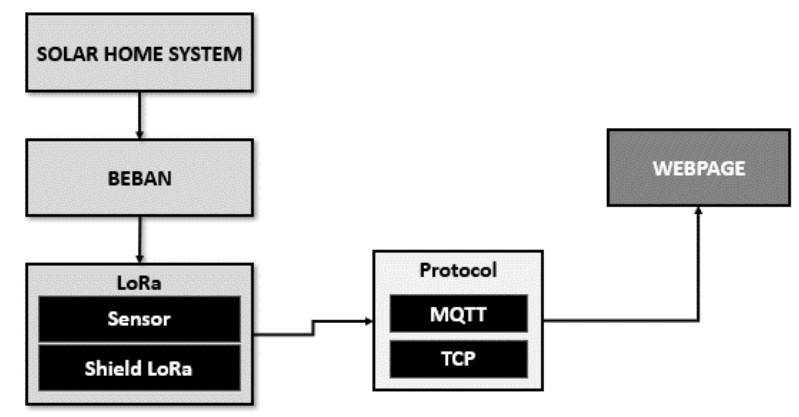

Gambar 3. Skema Sistem Monitoring

Data yang didapatkan oleh sensor Arus dan Tegangan, dikirimkan secara periodik melalui shield komunikasi LoRa dan diterima oleh Gateway, penerimaan data pada gateway dilakukan dengan protocol MQTT, format instruksi yang digunakan untuk memastikan data tertangkap menggunakan perintah "subscribe" sebagai berikut:

\begin{tabular}{|c|c|}
\hline MQTT & IP \\
\hline Subscribe GatewayName/GatewayID & Ping Gateway IP \\
\hline
\end{tabular}




\section{Energi dan Kelistrikan: Jurnal Ilmiah}

Vol. 13, No. 1, Januari - Juni 2021, P-ISSN 1979-0783, E-ISSN 2655-5042

https://doi.org/10.33322/energi.v13i1.1149

Data yang didapatkan dari hasil tersebut berupa sekelompok informasi sebagai berikut:

\begin{tabular}{|l|r|r|r|r|r|r|}
$\begin{array}{l}\text { channels } \\
923200000\end{array}$ & SpreadFactor & RSSI & Powers & Arus & Voltase & Waktu \\
\hline 923400000 & 10 & -25.0 & 960 & 4 & 21,170 & $2020-10-2807: 13: 00$ \\
\hline 923200000 & 10 & -23.0 & 960 & 4 & 21,170 & $2020-10-2807: 13: 10$ \\
\hline 923400000 & 10 & -24.0 & 960 & 4 & 21,170 & $2020-10-2807: 13: 21$ \\
\hline 923400000 & 10 & -25.0 & 960 & 4 & 21,170 & $2020-10-2807: 13: 31$ \\
\hline 923200000 & 10 & -24.0 & 960 & 4 & 21,120 & $2020-10-2807: 13: 41$ \\
\hline 923400000 & 10 & -23.0 & 2,080 & 4 & 21,140 & $2020-10-2807: 13: 51$ \\
\hline 923200000 & 10 & -23.0 & 15,520 & 10 & 21,130 & $2020-10-2807: 14: 01$ \\
\hline 923200000 & 10 & -24.0 & 50,880 & 26 & 21,150 & $2020-10-2807: 14: 11$ \\
\hline 923400000 & 10 & -24.0 & 51,040 & 27 & 21,110 & $2020-10-2807: 14: 22$ \\
\hline 10 & -22.0 & 50,400 & 26 & 21,110 & $2020-10-2807: 14: 32$ \\
\hline
\end{tabular}

Gambar 4. Data Hasil transmisi LoRa

Karakteristik khas menggunakan LoRa adalah pada nilai Spread Factor dan Channel yang berasal dari End node dan Gateway, nilai SpreadFactor secara otomatis akan menyesuaikan pada kondisi jarak End Node terhadap Gateway, dan nilai channel menunjukkan kemampuan Gateway dalam menerima paket data yang dikirimkan oleh End Node.

Berdasarkan pada data di Gambar 3, Penyajian informasi sistem monitoring dibuat untuk masing masing kelompok berdasarkan data yang diterima dalam skema sistem tersebut diatas.

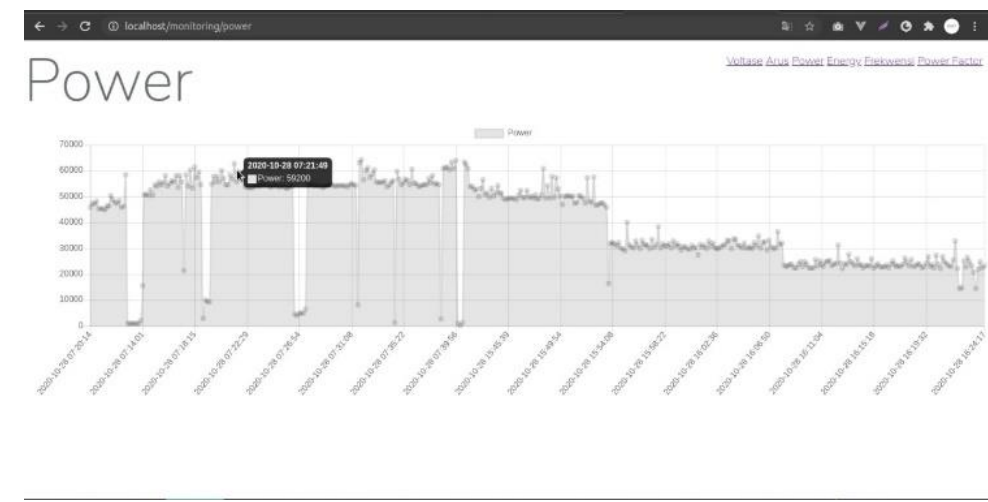

Gambar 5. Tampilan Informasi Power

Penayangan informasi power didapatkan berdasarkan penggunaan beban yang dibaca oleh sensor, kemudian data tersebut dikirimkan melalui sistem LoRa.

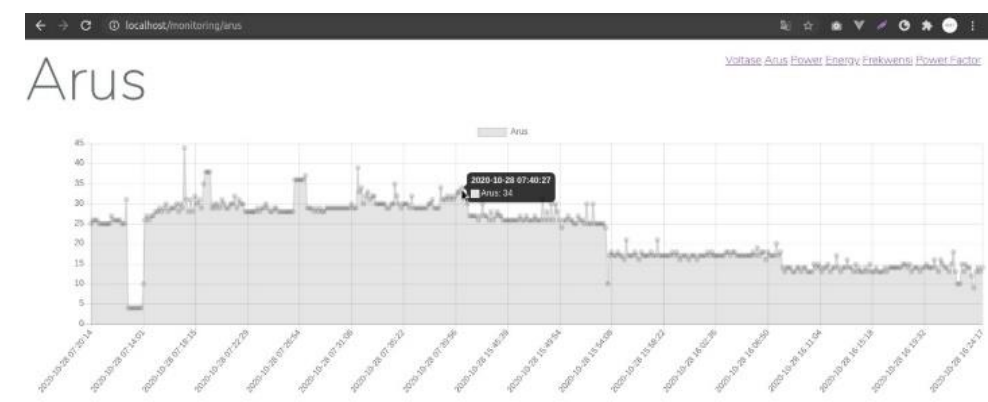

Gambar 6. Tampilan Informasi Arus 
Tampilan informasi Arus menunjukkan waktu pengiriman data dari End Node menuju Gateway, dan juga dipengaruhi oleh Beban yang terhubung pada rangkaian Listrik.

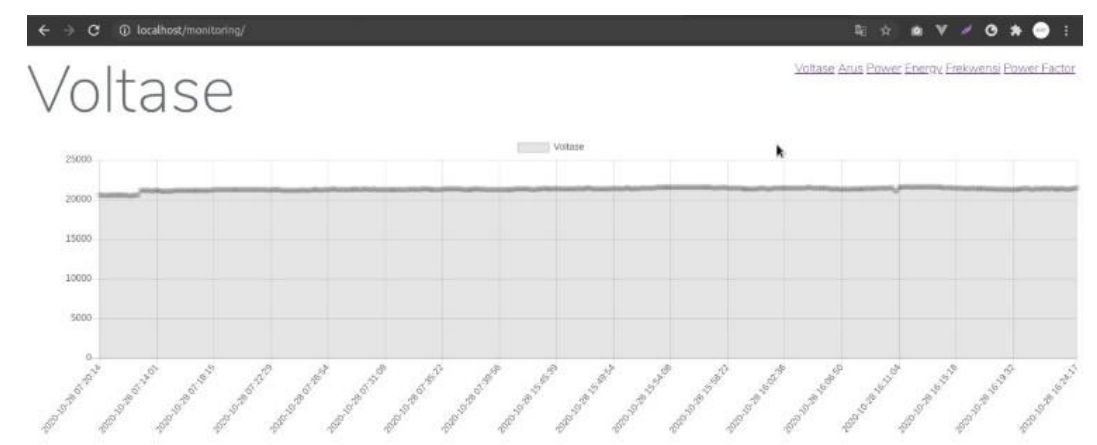

Gambar 7. Tampilan Informasi Voltase

Informasi yang terakhir adalah mengenai Voltase atau tegangan yang didapatkan oleh sensor, besar nilai tersebut didapatkan berdasarkan potensi energi yang mengalir pada rangkaian listrik dalam skema yang dibuat pada gambar 6 .

\section{KESIMPULAN DAN SARAN}

Penggunaan Long Range radio untuk mendukung pengembangan sistem cerdas dalam kelistrikan khususnya pada monitoring secara real time dapat diandalkan dengan mempertimbangkan jumlah Bytes data yang mampu dikirim setiap periodenya. Saran untuk pengembagan lebih jauh, RSSI atau Receive Signal Strength Indicator dan Spread Factor harus dilengkapi dengan pengukuran jarak dari Gateway ke setiap End Node guna memastikan kualitas pengiriman data dengan berbagai kondisi hambatan.

\section{UCAPAN TERIMAKASIH}

Penulis mengucapkan terima kasih kepada kementerian Riset dan Teknologi yang telah memberikan Hibah Penelitian Dosen Pemula Tahun Anggaran 2020, dan juga Institut Teknologi PLN yang telah memberi dukungan yang membantu pelaksanaan penelitian dan atau penulisan artikel.

\section{DAFTAR PUSTAKA}

[1] I. S. Hudan et al., "RANCANG BANGUN SISTEM MONITORING DAYA LISTRIK PADA KAMAR KOS BERBASIS INTERNET OF THINGS ( IOT ) Tri Rijianto Abstrak,” vol. 0, no. April, 2018.

[2] Semtech, "LoRa for Smart Utilities." [Online]. Available: https://info.semtech.com/hubfs/USECASE_SEMTECH_SMARTUTILITIES_BOOK_11081 9(WEB).pdf?hsLang=en-us. [Accessed: 07-Jun-2020].

[3] G. Wibisono, S. Gilang Permata, A. Awaludin, and P. Suhasfan, "Development of advanced metering infrastructure based on LoRa WAN in PLN Bali toward Bali Eco smart grid," 2017 Saudi Arab. Smart Grid Conf. SASG 2017, pp. 1-4, 2018, doi: 10.1109/SASG.2017.8356496.

[4] L. Germani, V. Mecarelli, G. Baruffa, and L. Rugini, "An IoT Architecture for Continuous Livestock Monitoring Using LoRa LPWAN,” 2019, doi: 10.3390/electronics8121435. 


\section{Energi dan Kelistrikan: Jurnal Ilmiah}

Vol. 13, No. 1, Januari - Juni 2021, P-ISSN 1979-0783, E-ISSN 2655-5042

https://doi.org/10.33322/energi.v13i1.1149

[5] S. Yudho, "Conceptual Design of Battery Energy Storage Monitoring System using LoRa," in 2020 International Seminar on Application for Technology of Information and Communication (iSemantic), 2020, pp. 374-377, doi: 10.1109/iSemantic50169.2020.9234217.

[6] S. Spinsante et al., "A LoRa enabled building automation architecture based on MQTT," 2017 AEIT Int. Annu. Conf. Infrastructures Energy ICT Oppor. Foster. Innov. AEIT 2017, vol. 2017-Janua, pp. 1-5, 2017, doi: 10.23919/AEIT.2017.8240560. 